\title{
Negative Impact of Total Body Irradiation on the Antitumor Activity of Rhenium-(I)-diselenoether
}

\author{
PHILIPPE COLLERY ${ }^{1,2 *}$, FRANCOIS SANTONI $^{2,3}$, AHMED MOHSEN $^{4}$, \\ CAROLINE MIGNARD ${ }^{5}$ and DIDIER DESMAELE ${ }^{4}$ \\ ${ }^{1}$ Society for the Coordination of Research, Algajola, France; \\ ${ }^{2}$ Research and Development Center for the Therapeutic Use of Organo-Metallic Compounds, \\ Maymard Polyclinic, Bastia, France; \\ ${ }^{3}$ Laboratory of the Corsican Office of Hydraulic Equipment, Bastia, France; \\ ${ }^{4}$ UMR CNRS 8612, Galien Institute, Faculty of Pharmacy, University Paris-Saclay, Châtenay-Malabry, France; \\ ${ }^{5}$ Oncodesign, Dijon, France
}

\begin{abstract}
It has been shown that a rhenium-(I)-diselenoether complex had significant antitumor activity in MDA-MB231 tumor-bearing mice after repeated oral or intraperitoneal administrations for 4 weeks at safe doses of $10 \mathrm{mg} / \mathrm{kg} /$ day. It has also been suggested that lower doses could be as effective as this dose. We, thus, tested two doses (5 and $10 \mathrm{mg} / \mathrm{kg}$ ). The drug was orally administered daily by gavage for 4 weeks and for a further 2 weeks with or without $15 \mathrm{mg} / \mathrm{kg}$ paclitaxel treatment (intravenously, once a week). This experiment was performed in MDA-MB 231 tumor-bearing mice, as a model of resistant breast tumor. However, in contrast to previous studies, the mice were pretreated with total body irradiation to increase the tumor growth. These two doses were safe, even in combination with paclitaxel. The expected tumor regression was not observed with the rhenium-(I)-diselenoether complex, and there was even a significant increase of the tumor volume in mice treated with $10 \mathrm{mg} / \mathrm{kg}$ versus controls. No synergism was observed with paclitaxel. We comment on the possible negative impact of radiotherapy on the antitumor activity of the drug. Plasma and tumor rhenium and selenium concentrations are also reported.
\end{abstract}

It has been shown that a prolonged oral administration of amphiphilic rhenium-(I)-diselenoether complex allowed a dose-dependent uptake of the two major components of this

This article is freely accessible online.

Correspondence to: Philippe Collery, Society for the Coordination of Therapeutic Research, 20220 Algajola, France. E-mail: philippe.collery@gmail.com

Key Words: Rhenium (Re), selenium (Se), in vivo experiment, MDA-MB231, bioluminescence, mice, breast cancer, radiotherapy. drug, rhenium ( $\mathrm{Re}$ ) and selenium (Se) in healthy tissues, with highest uptake by the liver (1). Assays of these two elements have not yet been performed in tumors

The combination of Se with a metal has already been described, with nickel as the metal (2). In that case, the presence of $\mathrm{Se}$ in the active site of hydrogenase enhanced its enzymatic property. Selective incorporation of Se into the active site of the molybdenum-iron (Mo-Fe) protein is essential for the catalytical effect of nitrogenase (3). Ironselenium ferredoxin with two clusters [4Fe-4Se] is present in the active site of a hydrogenase (4), with the same role as the iron-sulfur ferredoxin as a two-electron carrier.

It is known that $\mathrm{Re}$ is able to bind DNA reversibly and that $\mathrm{Re}$ is found in the nucleus of malignant cells after the administration of Re-diselenoether $(1,5)$. It was also shown that the Re-diselenoether formed mono-adducts and bisadducts with a methyl-guanine, but also liberated the weakly chelating diselenoether ligand [supplementary material in (5)].Therefore we can hypothesize that while the Re core will have a role by interacting with DNA guanine bases, the diselenoether ligand will take Se to other targets.

The anticancer activity of Re-diselenother has been demonstrated in experimental models of resistant triplenegative breast tumors (MDA-MB231), in malignant cells in culture, as well as after oral (5) or intraperitoneal administration (6) to tumor-bearing mice, at a daily dose of $10 \mathrm{mg} / \mathrm{kg} /$ day for 4 weeks, which was safe for the animals. The Re-diseleno ether compound we used, constituted an original chemical combination, and we aimed to complete the investigation of its biological role in an experimental model of cancer.

The aim of this experiment was to test a lower dose of $5 \mathrm{mg} / \mathrm{kg}$ and to compare it with a $10-\mathrm{mg} / \mathrm{kg}$ dose. We evaluated the Re-complex as a single agent and in combination with paclitaxel, considered as a standard 
chemotherapy for metastatic triple-negative breast cancer, in order to look for synergism between these two drugs. It was proposed that the Re-diselenoether compound could belong to a new class of anticancer drugs, as a modulator of the redox status, and that plasma Se concentrations could help monitor the therapy. We, therefore, assayed the Se concentrations in plasma and in tumors. To evaluate the uptake of Re by the tumors, we assayed the concentrations in the tumors and compared them with the plasma $\mathrm{Re}$ concentrations.

We looked in this study for a dose-effect between two doses of $\operatorname{Re}(\mathrm{I})$ - diselenoether, 5 to $10 \mathrm{mg} / \mathrm{kg}$, orally administered for 4 weeks. Three groups were thus compared, a control one and two treated with the corresponding 5 and $10 \mathrm{mg} / \mathrm{kg}$ doses. We also attempted, in a second period of 2 weeks, to look for a synergism with paclitaxel, one of the most active drugs in the treatment of triple-negative breast cancer.

Total body irradiation was applied before the inoculation of cancer cells. This radiotherapy was not concentrated on the tumor site but used as a non-selective irradiation to reduce the immune system, favoring the transplantation of the tumors and increasing tumor growth. However, this radiotherapy may induce biological changes, especially in the redox potential of the healthy and tumor cells and these potential effects should be taken into consideration when explaining the results.

\section{Materials and Methods}

This study was performed at Oncodesign laboratory (Dijon, France).

Animals. Forty-five healthy female Balb/C nude mice, 7 weeks old, were obtained from Charles River (L'Arbresles, France). These immunodeficient mice were observed for 7 days in a specificpathogen-free (SPF) animal care unit before starting any procedure. The animal care unit is authorized by the French ministries of Agriculture and Research (agreement no. A21231011EA). Animal experiments were performed according to ethical guidelines of animal experimentation and the English guidelines for welfare of animals in experimental neoplasia (7). All procedures with animals were submitted to the Animal Care and Use Committee of Oncodesign (CNREEA Agreement $\mathrm{N}^{\circ}$ 91). Animals were maintained in rooms under controlled conditions of temperature $\left(23 \pm 2^{\circ} \mathrm{C}\right)$,

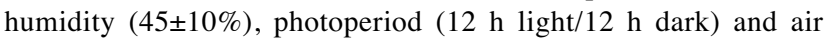
exchange. Animals were maintained in SPF conditions. Room temperature and humidity were continuously monitored. The air handling system was programmed for 14 air changes/h, with no recirculation. Fresh outside air passed through a series of filters, before being diffused evenly into each room. A positive pressure $(20 \pm 4 \mathrm{~Pa})$ was maintained in the experimentation room to prevent contamination or the spread of pathogens within a rodent colony. All personnel working under SPF conditions followed specific guidelines regarding hygiene and clothing when they enter the animal husbandry area (International Rules for the husbandry). Animals were housed in polycarbonate cages (Techniplast, Limonest, France) that were equipped to provide food and water.
The standard area cages used were $800 \mathrm{~cm}^{2}$ with 10 mice per cage (from the same group) according to internal standard operating procedures. Bedding for animals was sterile corn cob bedding (LAB COB 12, SERLAB, Cergy-Pontoise, France), replaced twice a week. Animal food was purchased from SSNIF (Soest, Germany). Immunodeficient animal food (ref: V1246-703) was provided ad libitum, being placed in the metal comportment at the top of the cage. Water was also provided ad libitum from water bottles equipped with rubber stoppers and sipper tubes. Water bottles were cleaned and sterilized by autoclave and replaced twice a week. Water was sterilized by sterile filtration and replaced twice a week. Animals were identified with two different numbers engraved on two ear tags. Each cage was labeled with a specific code.

Cancer cell line and cell culture conditions. MDA-MB231 cancer cell line is a cell line derived from a human breast adenocarcinoma. It was obtained from the American Tissue Culture Collection (LGC, Molsheim, France).

Tumor cells were grown as an adherent monolayer at $37^{\circ} \mathrm{C}$ in a humidified atmosphere $\left(5 \% \mathrm{CO}_{2}, 95 \%\right.$ air). The culture medium was RPMI-1640 containing $2 \mathrm{mM}$ L-glutamine (Lonza, Verviers, Belgium) supplemented with $10 \%$ fetal bovine serum (Lonza). For experimental use, tumor cells were detached from the culture flask by a 5 min treatment with trypsin-versene (Lonza), in Hanks' medium without calcium or magnesium (Lonza) and neutralized by the addition of complete culture medium. The cells were counted in a hemocytometer and their viability was assessed by $0.25 \%$ trypan blue exclusion assay. Mycoplasma detection was performed using MycoAlert Mycoplasma Detection Kit (Lonza).

Experimental design. Tumors were induced subcutaneously by injecting $10 \times 10^{6}$ MDA-MB-231 cells in $200 \mu \mathrm{l}$ of RPMI-1640 containing matrigel (50:50, v:v; BD Biosciences, Le Pont de Claix, France) into the right flank of 45 female animals. MDA-MB-23I tumor cell implantation was performed 48 hours after whole-body irradiation with a $\gamma$-source $\left(2 \mathrm{~Gy}{ }^{60} \mathrm{Co}\right.$; BioMep, Bretenières, France). The day of tumor induction was considered as day 0 . The length and width of the tumors were measured and recorded twice a week with calipers and the tumor volumes were established by the formula: (width ${ }^{2} \times$ length) $/ 2$.

Part A: Treatment started when the tumors reached a mean volume of $230 \mathrm{~mm}^{3}$. Thirty out of 45 mice were randomized according to their individual tumor volume into three groups, of 10 animals each, using Vivo manager ${ }^{\circledR}$ software (Biosystemes, Couternon, France). A statistical test (analysis of variance) was performed to test for homogeneity between groups. The treatments were orally [per os, (p.o.)] administered with a cannula by gavage. The animals from group 1 received one daily p.o. administration of vehicle (dissolved in sterilized water) for 28 consecutive days. The animals from group 2 received one daily p.o. administration of Rediseleno-ether (synthesized at Galien Institute, Paris, France) at 5 $\mathrm{mg} / \mathrm{kg}$ for 28 consecutive days. The animals from group 3 received one daily p.o. administration of Re-diseleno-ether at $10 \mathrm{mg} / \mathrm{kg}$ administration for 28 consecutive days.

Part B: On day 39, mice from each group above were randomized into two subgroups (groups $a$ and $b$ ) of five mice each. The animals from group 1a received one daily p.o. administration of vehicle for 2 more weeks. The animals from group $1 \mathrm{~b}$ received one daily p.o. administration of vehicle for 2 weeks in combination with one i.v. injection of paclitaxel (Bristol-Meyers, Rueil- 
Malmaison, France) at $15 \mathrm{mg} / \mathrm{kg}$ on days 39 and 46 . The animals from groups 2 and 3 received one daily p.o. administration of Rediselenoether at $5 \mathrm{mg} / \mathrm{kg} / 24 \mathrm{~h}$ (group 2) or $10 \mathrm{mg} / \mathrm{kg} / 24 \mathrm{~h}$ (group 3) for 2 weeks with one i.v. injection of paclitaxel at $15 \mathrm{mg} / \mathrm{kg}$ on days 39 and 46 (groups $2 b$ and $3 b$ ). The animals from group 1a, $2 a$ and $3 \mathrm{a}$ did not receive paclitaxel. Treatments with paclitaxel were performed 3 to 4 hours after treatment with Re-diselenoether.

Animal monitoring and sacrifice. Study management (collection, measurements, raw data, lethality, behavior, treatment and results of autopsy) were recorded and analyzed using Vivo manager ${ }^{\circledR}$ software (Biosystemes). Animal viability and behavior were recorded every day. Body weights were measured twice a week.

Isoflurane (Baxter, France) was used to anesthetize the animals before tumor cell inoculation and before sacrifice. During the course of the experiment, animals were to be sacrificed by cervical dislocation under anesthesia if any of the following signs occurred: signs of suffering (cachexia, weakening), treatment-related toxicity (hunching, convulsions), tumor growing to $10 \%$ of body weight, tumor ulcerating and remaining open, position of tumor interfering with movement/feeding, $15 \%$ body weight loss for 3 consecutive days or $20 \%$ body weight loss for 1 day, clinical signs of tumor development (hindback paralysis, failure to groom, restlessness, abnormal posture or changes in resting posture, loss of mobility, paralysis etc.). Animals were sacrificed when the subcutaneous tumors reached a maximum volume of $2000 \mathrm{~mm}^{3}$. It was for this latter reason that treatments were stopped at day 52 and animals were sacrificed on day 53 .

Blood collection and assays of Re and Se. Twenty-four hours after the last treatment, blood from mice from all groups was collected and immediately transferred to tubes containing lithium-heparin as anticoagulant (Capiject ${ }^{\circledR}$ TERUMO ${ }^{\circledR}$ ), Guyancourt, France) thoroughly mixed and centrifuged at $1,174 \times g$ for $10 \mathrm{~min}$ at $4^{\circ} \mathrm{C}$. The resulting plasma was collected, weighed and the volume of the plasma sample was determined. The plasma was immediately mineralized in fuming $\mathrm{HNO}_{3}$ as a standard procedure. Three milliliters of oxygenated $\mathrm{H}_{2} \mathrm{O}$ were added to plasma in a Falcon tube and maintained at room temperature for $2 \mathrm{~h}$. The tubes were then incubated in a stove at $70^{\circ} \mathrm{C}$ for $2 \mathrm{~h}$ to obtain an homogenous solution. Finally, the samples were made to a final volume of $10 \mathrm{ml}$ per tube with ultrapure $\mathrm{H}_{2} \mathrm{O}_{2}$. The same procedure of mineralization was performed for the tumors, with quantification of the weight of the tumors after a precise dissection. Assays of not only Re and Se, but also $\mathrm{Mn}$, were performed by inductively-coupled mass spectrometry (ICP-Ms) from Perkin-Elmer (type Elan, BRC II, NF EN ISO 17294-1-2) with a detection limit of $1 \mu \mathrm{g} / \mathrm{ml}$.

\section{Results}

Efficacy. Results of the first part of the study (4 weeks of Re-diselenoether at two doses versus controls) are represented in Figure 1. Treatment with Re-diselenoether did not induce any antitumor effect, and even a significant increase $(p=0.006)$ of the tumor volumes in mice treated at the dose of $10 \mathrm{mg} / \mathrm{kg} / \mathrm{d}$ versus controls at day 39 was noted. The increase was not significant in mice treated at the dose of $5 \mathrm{mg} / \mathrm{kg} / \mathrm{d}$ versus controls due to greater individual variations in this group.

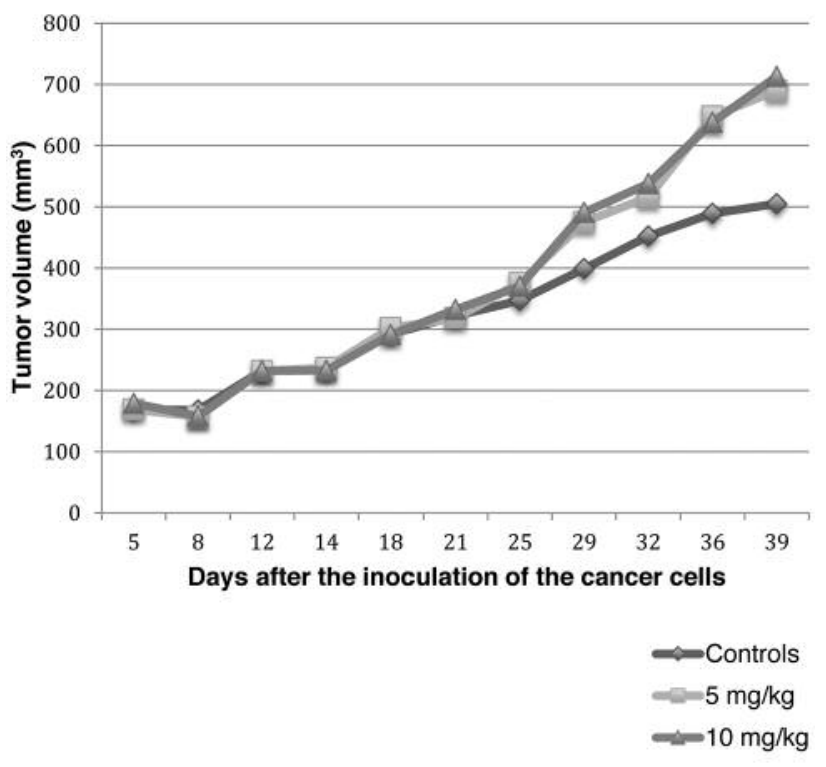

Figure 1. Evolution of tumor volume after a daily oral administration of Re(I)-diselenoether (5 and $10 \mathrm{mg} / \mathrm{kg} / \mathrm{d}$ ) for 4 weeks in MDA-MB231 tumor-bearing mice pre-treated with total body irradiation compared with controls, which received a vehicle treatment. The SD bars are not presented, but at day 39, the tumor volumes were significantly increased $(p=0.006)$ in mice treated at the dose of $10 \mathrm{mg} / \mathrm{kg}\left(713 \pm 101 \mathrm{~mm}^{3}\right)$ versus controls $\left(505 \pm 117 \mathrm{~mm}^{3}\right)$. The increase was not significant in mice treated at the dose of $5 \mathrm{mg} / \mathrm{kg}\left(690 \pm 243 \mathrm{~mm}^{3}\right)$ versus controls but individual variations were greater.

Concerning the second part of the study, treatment with or without paclitaxel at day 39 and 46, treatment with Rediselenoether did not favorably influence paclitaxel efficacy. The results are shown in Figure 2 and Table I. The tumor volumes increased in all subgroups from day 39 (the beginning of this second part of the experiment, with the first injection of paclitaxel) until day 53. The increase of tumor volume was less in all subgroups when paclitaxel was added. There was no synergism between paclitaxel and $\mathrm{Re}$ diselenoether. As shown in Table I, the tumor weight at day 53 (after dissection) was significantly lower in mice treated with paclitaxel versus controls $(p=0.0077)$ and significantly increased in mice treated with $10 \mathrm{mg} / \mathrm{kg}$ Re-diselenoether versus controls $(p=0.039)$.

Toxicity. No toxicity was observed, with no death or loss of weight. Re-diselenoether was well tolerated, even when paclitaxel was added to the treatment, for a total daily oral administration of 5 or $10 \mathrm{mg} / \mathrm{kg}$ Re-diselenoether for 6 weeks.

Re and Se assays. Results are expressed in Table I. There was no statistical difference in tumor or plasma $\mathrm{Re}$ and $\mathrm{Se}$ concentrations between subgroups, but there were only five 


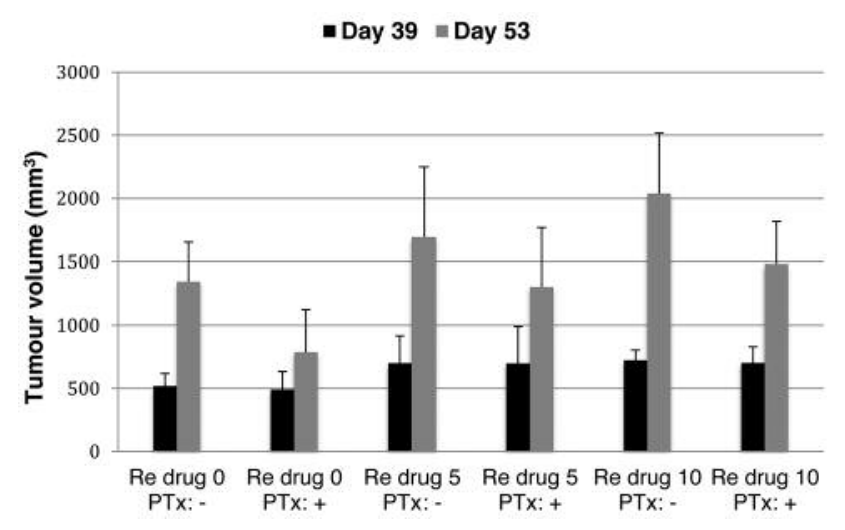

Figure 2. Evolution of tumor volume during the second part of the study, evaluating the effect of Re-diselenoether, with and without paclitaxel (PTX). Vehicle or Re-diselenoether was orally administered at 0, 5 or 10 $\mathrm{mg} / \mathrm{kg}$ for 2 weeks from days 39 to 52; paclitaxel was administered as an i.v. injection of $15 \mathrm{mg} / \mathrm{m}^{2}$ on days 39 and 46 . Mice were sacrificed on day 53. An increase of tumor was observed in all subgroups from days 39 to 53, even in mice treated with paclitaxel. At day 53, there was no statistical difference between any subgroup and the PTX-treated control subgroup. There was no synergism between Re-diselenoether and paclitaxel.

mice per subgroup and there had great individual variations. Moreover, sacrifice was $24 \mathrm{~h}$ after the last treatment with Rediselenoether, with an elimination of Re and Se during this period. The half-life of elimination of Re and Se after oral administration of Re-diselenoether is not known.

There was no presence of Re in the plasma and tumor in controls, as expected for a non-physiological metal, but there was a trend for an increase of Re concentration in the tumors in mice receiving $10 \mathrm{mg} / \mathrm{kg}$ versus those treated at the dose of $5 \mathrm{mg} / \mathrm{kg} \mathrm{Re}$-diselenoether. The doses of the Rediselenoether complex were not high enough to induce an increase in Se concentration. There was no significant difference in the between tumors and plasma $\mathrm{Re}$ and $\mathrm{Se}$ concentrations observed for the mice receiving 5 or $10 \mathrm{mg} / \mathrm{g}$ of Re-diselenoether. The plasma concentration could, therefore, be a good reflection of the corresponding tumor concentration and could be used as a marker for evaluating the tumor uptake of these two elements in further studies.

There was no influence of paclitaxel administration on $\mathrm{Re}$ and Se concentrations. We observed a very significant increase of $\mathrm{Mn}$ concentration in the tumors in mice receiving paclitaxel versus those that were treated with the vehicle $(p<0.0001)$ or with Re-diselenoether compound without paclitaxel $(p \leq 0.002)$.

\section{Discussion}

The results of this study are unexpected as they did not confirm the antitumor activity of the Re-diselenoether compound reported in two previous studies $(5,6)$, with the same experimental model of MDA-MB231-transplanted tumors in nude mice treated with the same dose of $10 \mathrm{mg} / \mathrm{kg} / \mathrm{d}$ of Re-diselenoether. Differences in the experimental conditions may partly explain the difference of results between three experiments. In the first published study, the Rediselenoether complex induced remarkable activity with a nearly complete regression of the tumors at the site of the primary tumor and a statistically significantly decrease in the number of pulmonary metastases (5). In the second study (6), there was a significant antitumor activity of the Rediselenoether complex, but not a complete regression of the tumors at the dose of $10 \mathrm{mg} / \mathrm{kg} /$ day. However, in these two experiments, the Re-diselenoether complex was active as an anticancer agent at a non-toxic daily dose of $10 \mathrm{mg} / \mathrm{kg} / \mathrm{d}$ for 4 weeks. In this new experiment, the effects of the Rediselenoether drug differed, even favoring tumor growth, and had no synergistic effect with paclitaxel.

In our opinion, the main difference between experiments was the pre-treatment with whole-body irradiation. Totalbody irradiation should completely suppress immunity, which is already at a low level in nude mice. If the activity of the Re-diselenoether drug is mediated by the immune system, it cannot be observed in this experimental model. This is an important factor to take into consideration. Re may have positive effects on the immune system, according to the review of Terenzi et al. (8). Favorable effects of adapted doses of Se on the immune system have already been published (9-13). Se seems to be essential for the synthesis of interleukin-6 and interferon- $\gamma$ (14).

Due to the irradiation, the use of matrigel and the great number of transplanted tumor cells, the tumor volumes were 10 times greater in this study $\left(200 \mathrm{~mm}^{3}\right)$ at the beginning of treatments than in the previously published one (5), where the tumors were of about only $20 \mathrm{~mm}^{3}$. In this study, the tumor cells were subcutaneously injected, not into the fat mammary pad and without induction of metastases, but with rapid growth of the primary tumor, reaching $2,000 \mathrm{~mm}^{3}$ at the end of the experiment.

As previously mentioned, Re-diselenoether compound is suggested to be a redox modulator (6), due to the two components, $\mathrm{Re}$, which is a metal with a great number of oxidation states (similarly to $\mathrm{Mn}$ ), and $\mathrm{Se}$, which is an element with dual effects, either prooxidant or antioxidant. It is thus not surprising that we were also able to observe opposing effects of Re-diselenoether. This may be related to an increased redox potential, with a high production of free radicals and a decrease of the antioxidant capacity of the cells following whole-body irradiation. It was noted that radiotherapy increased the prooxidant status in patients with cancer (14). In our study, whole-body irradiation firstly concerned healthy cells, as this irradiation was administered before the inoculation of cancer cells. This may increase 
Table I. Tumor weights, plasma and tumor concentrations of Re, Se and Mn at sacrifice, on day 53, 24 h after the last treatment with Rediselenoether. Assays of Re, Se and Mn were performed by inductively-coupled mass spectrometry (ICP-Ms). Results are expressed as the mean $\pm S D$. The tumor weight was significantly reduced in mice treated with paclitaxel compared with controls $(p=0.0077)$ and significantly increased in mice treated with $10 \mathrm{mg} / \mathrm{kg}$ Re-diselenoether compared with controls ( $p=0.039)$. There was a non-significant increase of tumor Re concentration in mice treated with Re-diselenoether at $10 \mathrm{mg} / \mathrm{kg} /$ day versus those treated at $5 \mathrm{mg} / \mathrm{kg} /$ day, with and without paclitaxel, but no difference in the plasma Re. No significant increase of Se was observed in the tumors nor in the plasma in treated mice versus those not receiving Re-diselenoether. Paclitaxel did not significantly modify the Re and Se concentrations, but significantly increased the tumor Mn concentration in all subgroups receiving paclitaxel compared with controls $(p<0.002)$. Similar concentrations of Re and Se were observed in tumors and in plasma. The statistical analysis only concerned five mice per subgroup and only major changes could have been observed. The uptake of Re in tumors after oral administration of Re-diselenoether was the main result.

\begin{tabular}{|c|c|c|c|c|c|c|}
\hline \multirow[b]{2}{*}{ Treatment } & \multicolumn{2}{|c|}{$\mathrm{Re}$, mean $\pm \mathrm{SD}$} & \multicolumn{2}{|c|}{$\mathrm{Se}$, mean $\pm \mathrm{SD}$} & \multirow{2}{*}{$\frac{\text { Mn, mean } \pm \text { SD }}{\text { Tumor }(\mu \mathrm{g} / \mathrm{kg})}$} & \multirow[b]{2}{*}{ Tumor weight $(\mathrm{g})$} \\
\hline & Tumor $(\mu \mathrm{g} / \mathrm{kg})$ & Plasma $(\mu \mathrm{g} / 1)$ & Tumor $(\mu \mathrm{g} / \mathrm{kg})$ & Plasma $(\mu \mathrm{g} / \mathrm{l})$ & & \\
\hline Controls & 0 & 0 & $351 \pm 56$ & $255 \pm 104$ & $82 \pm 8$ & $1.36 \pm 0.44$ \\
\hline paclitaxel & 0 & 0 & $256 \pm 17$ & $220 \pm 45$ & $128 \pm 13^{*}$ & $0.53 \pm 0.2 *$ \\
\hline Re-diselenoether, $5 \mathrm{mg} / \mathrm{kg}$ & $63 \pm 34$ & $50 \pm 43$ & $417 \pm 122$ & $245 \pm 99$ & $80 \pm 12$ & $1.49 \pm 0.39$ \\
\hline $5 \mathrm{mg} / \mathrm{kg}$ Re-diselenoether + paclitaxel & $76 \pm 61$ & $65 \pm 52$ & $334 \pm 30$ & $255 \pm 137$ & $110 \pm 11 *$ & $1.19 \pm 0.39$ \\
\hline $10 \mathrm{mg} / \mathrm{kg}$ Re-diselenoether & $91 \pm 49$ & $190 \pm 214$ & $402 \pm 32$ & $365 \pm 210$ & $73 \pm 9$ & $2.02 \pm 0.4 *$ \\
\hline $10 \mathrm{mg} / \mathrm{kg} \mathrm{Re}$-diselenoether + paclitaxel & $89 \pm 20$ & $60 \pm 14$ & $366 \pm 28$ & $235 \pm 22$ & $113 \pm 11 *$ & $1.34 \pm 0.37$ \\
\hline
\end{tabular}

*Statistically significantly different from controls.

production of reactive oxygen species (ROS) in healthy cells and might induce a loss a selectivity of Se for cancer cells after administration of Re-diselenoether. This could be an explanation for the lack of increasing Se concentrations in our study in mice receiving the Re-diselenoether drug versus the others. In contrast, in a previous study, the $\mathrm{Se}$ concentration increased in plasma and tissues after oral administration of $10 \mathrm{mg} / \mathrm{kg} / \mathrm{d}$ of Re-diselenoether versus controls and significantly much more increased after a $40 \mathrm{mg} / \mathrm{kg}$ dose (1). A dose effect was clearly observed. This dose effect was not observed in the present study. Nevertheless, thanks to this study, we showed uptake of Re in tumors after the administration of the Re-diselenoether drug, with similar concentrations in plasma.

We observed a very significant effect of paclitaxel on tumor Mn concentration which is a metal with a great number of oxidation states, like Re, but we are at present unable to explain these results.

The Se level is considered a marker of the antioxidant status. The plasma Se level is reduced in patients with cancer (6). Radiotherapy induces a much greater decrease of plasma Se level in patients with cancer. For example, It was noted in patients treated by radiotherapy for breast cancer that the mean serum Se level dropped from $86.4 \mu \mathrm{g} / \mathrm{l}$ before radiotherapy to $47.8 \mu \mathrm{g} / \mathrm{l}$ after it (15). In another study of 95 patients with brain metastases from non-small cell lung cancer, the mean plasma Se level decreased from $90.4 \mu \mathrm{g} / \mathrm{l}$ before radiotherapy to $56.3 \mu \mathrm{g} / \mathrm{l}$ after radiotherapy of the brain metastases (16) and this difference was statistically significant in a multivariate analysis independently of age, body mass index, smoking, alcoholism, prior chemotherapy and pathological types. This is why Se treatments have been discussed for reducing radiation-associated side-effects (17, 18 ), but without definitive conclusions.

A decrease in plasma Se concentration was also observed in breast tumor-bearing mice, as well as a decrease in glutathione peroxidase activity, both of them indicators of a low antioxidant status, with an increase in plasma concentrations of vascular endothelial growth factor and in malondialdehyde, reflecting the production of ROS and a pro-oxidant status (19). An oral treatment with $\mathrm{Se}$, as $\mathrm{Se}$ yeast, for 14 days was able to increase the plasma $\mathrm{Se}$ concentration in breast tumor-bearing mice but with an increase in malondialdehyde products, a decrease in erythrocyte Se-dependent glutathione peroxidase activity, an increase in concentrations of Th1-derived cytokines and a decrease in Th2-type interleukin-4, while tumor progression was inhibited (20). The Se treatment was thus active against cancer, greatly increasing the pro-oxidant baseline status. Se nanoparticles have been shown to be able to potentiate radiotherapy, and again at doses increasing the production of ROS in the cancer cells (21). Cancer cells already have a pro-oxidant status compared with normal cells and it is by further increasing the production of ROS that chemotherapeutic agents usually kill them (6). In our study, the Re-diselenoether compound may have induced an antioxidant status, not only in healthy cells, thereby protecting them, but also in cancer cells. If the antioxidant effect is not significant enough to inhibit cancer growth, it may on the contrary favor tumor growth. 
We did not observe any synergism between paclitaxel and the Re-diselenoether drug, but a synergism between taxanes and Se was demonstrated with docetaxel (22), and paclitaxel (23) in other studies. In our study, we did not observe an increase of the Se concentration after the Re-diselenoether treatment and we may postulate that the level of Se in the tumors was therefore not capable of increasing the oxidant status in the cancer cells.

Not all Se compounds will have the same effect on the redox status and different flurorescent markers may be used in cells to compare them (24), e.g. 2',7'-dichlorodihydrofluorescein diacetate for the production of total ROS, knowing that this reagent mainly reacts with peroxides; MitoSOX Red to assay mitochondrial $\mathrm{O}_{2}{ }^{\circ-}$ more specifically; and the Singlet Oxygen Sensor Green reagent for the production of ${ }^{1} \mathrm{O}_{2}$. We aim to compare the effect of the Rediselenoether drug with antioxidants and pro-oxidants by these methods in both normal and in cancer cells. We need to know if the Re-diselenoether drug acts as an oxidant or antioxidant according to experimental conditions and if these dual effects may explain the results found in this study, which were opposite to those expected.

\section{Conclusion}

Under the experimental conditions of this study, the Rediselenoether drug had no antitumor activity, but this model is far from a physiological one, with a very aggressive tumor type. We confirmed lack of toxicity of the Re-diselenoether drug after daily oral administration by gavage for 4 weeks at $10 \mathrm{mg} / \mathrm{kg} / 24 \mathrm{~h}$ and for an additional period of 2 weeks in a combination with an i.v. injection of paclitaxel at a high dose of $15 \mathrm{mg}$ per week. The dose of $10 \mathrm{mg} / \mathrm{kg} / 24 \mathrm{~h}$ of Rediselenoether can definitely be considered safe for mice, for at least 6 weeks, even with a combined paclitaxel treatment at conventional doses. The lack of activity of the Rediselenoether drugs in completely immunosuppressed mice (due to prior total-body irradiation) may indicate the need to explore the effect of Re-diselenoether on the immune system. We also need to precisely determine the effect of the compound as a potential redox modulator. Plasma concentrations of $\mathrm{Re}$ and $\mathrm{Se}$ may well reflect the corresponding tumor concentrations and other studies are required to determine if they may be helpful in monitoring the efficacy of Re-diselenoether drug in more physiological cancer models, without prior whole-body irradiation, which is probably a model to be completely excluded.

\section{Acknowledgements}

The Authors would like to thank the Conseil Départemental de Haute Corse and association Néa from Corsica, for moral and financial support.

\section{References}

1 Collery P, Bastian G, Santoni F, Mohsen A, Wei M, Collery T, Tomas A, Desmaele D and D' Angelo J: Uptake and efflux of rhenium in cells exposed to rhenium diseleno-ether and tissue distribution of rhenium and selenium after rhenium diselenoether treatment in mice. Anticancer Res 34: 1679-1690, 2014.

2 Wombwell C and Reisner E: Synthetic active site model of the [NiFeSe] hydrogenase. Chemistry 21: 8096-8104, 2015.

3 Spatzal T, Perez KA, Howard JB and Rees DC: Catalysisdependent selenium incorporation and migration in the nitrogenase active site iron-molybdenum cofactor. Elife 4: e11620, 2015.

4 Moulis JM and Meyer J: Characterization of the seleniumsubstituted 2 [4Fe-4Se] ferredoxin from Clostridium pasteurianum. Biochemistry 21: 4762-4771, 1982.

5 Collery P, Mohsen A, Kermagoret A, Corre S, Bastian G, Tomas A, Wei M, Santoni F, Guerra N, Desmaele D and d' Angelo J: Antitumor activity of a rhenium (I)-diselenoether complex in experimental models of human breast cancer. Invest New Drugs 33: 848-860, 2015.

6 Collery P, Santoni F, Ciccolini J, Tran TNN, Mohsen A and Desmaele D: Dose effect of rhenium (I)-diselenoether as anticancer drug in resistant breast tumor-bearing Mice after repeated administration. Anticancer Res 36: in press, 2016.

7 Workman P, Aboagye EO, Balkwill F, Balmain A, Bruder G, Chaplin DJ, Double JA, Everitt J, Farningham DA, Glennie MJ, Kelland LR, Robinson V, Stratford IJ, Tozer GM, Watson S, Wedge SR, Eccles SA and Committee of the National Cancer Research I: Guidelines for the welfare and use of animals in cancer research. Br J Cancer 102: 1555-1577, 2010.

8 Terenzi A, Pirker C, Keppler BK and Berger W: Anticancer metal drugs and immunogenic cell death. J Inorg Biochem doi: 10.1016/j.jinorgbio.2016.06.0212016.

9 Carlson BA, Yoo MH, Sano Y, Sengupta A, Kim JY, Irons R, Gladyshev VN, Hatfield DL and Park JM: Selenoproteins regulate macrophage invasiveness and extracellular matrixrelated gene expression. BMC immunology 10: 57, 2009.

10 Hagemann-Jensen M, Uhlenbrock F, Kehlet S, Andresen L, Gabel-Jensen C, Ellgaard L, Gammelgaard B and Skov S: The Selenium metabolite methylselenol regulates the expression of ligands that trigger immune activation through the lymphocyte receptor NKG2D. J Biol Chem 289: 31576-31590, 2014.

11 Huang Z, Rose AH and Hoffmann PR: The role of selenium in inflammation and immunity: from molecular mechanisms to therapeutic opportunities. Antioxid Redox Signal 16: 705-743, 2012.

12 Latorre AO, Caniceiro BD, Fukumasu H, Gardner DR, Lopes FM, Wysochi HL, Jr., da Silva TC, Haraguchi M, Bressan FF and Gorniak SL: Ptaquiloside reduces NK cell activities by enhancing metallothionein expression, which is prevented by selenium. Toxicology 304: 100-108, 2013.

13 Shrimali RK, Irons RD, Carlson BA, Sano Y, Gladyshev VN, Park JM and Hatfield DL: Selenoproteins mediate T cell immunity through an antioxidant mechanism. J Biol Chem 283: 20181-20185, 2008.

14 Tsuji PA, Carlson BA, Anderson CB, Seifried HE, Hatfield DL and Howard MT: Dietary selenium levels affect selenoprotein expression and support the Interferon-gamma and IL-6 Immune response pathways in mice. Nutrients 7: 6529-6549, 2015. 
15 Franca CA, Nogueira CR, Ramalho A, Carvalho AC, Vieira SL and Penna AB: Serum levels of selenium in patients with breast cancer before and after treatment of external beam radiotherapy. Ann Oncol 22: 1109-1112, 2011.

16 Zeng YC, Xue M, Chi F, Xu ZG, Fan GL, Fan YC, Zheng MH, Zhong WZ, Wang SL, Zhang ZY, Chen XD, Wu LN, Jin XY, Chen W, Li Q, Zhang XY, Xiao YP, Wu R and Guo QY: Serum levels of selenium in patients with brain metastases from nonsmall cell lung cancer before and after radiotherapy. Cancer/ Radiothérapie 16: 179-182, 2012.

17 Buntzel J, Micke O, Kisters K, Bruns F, Glatzel M, Schonekaes K, Kundt G, Schafer U and Mucke R: Selenium substitution during radiotherapy of solid tumours - laboratory data from two observation studies in gynaecological and head and neck cancer patients. Anticancer Res 30: 1783-1786, 2010.

18 Tabassum A, Bristow RG and Venkateswaran V: Ingestion of selenium and other antioxidants during prostate cancer radiotherapy: a good thing? Cancer Treat Rev 36: 230-234, 2010.

19 Guo $\mathrm{CH}$, Hsia S and Chen PC: Distribution of selenium and oxidative stress in breast tumor-bearing mice. Nutrients 5: 594607,2013

20 Guo CH, Hsia S, Hsiung DY and Chen PC: Supplementation with selenium yeast on the prooxidant-antioxidant activities and antitumor effects in breast tumor xenograft-bearing mice. J Nutr Biochem 26: 1568-1579, 2015.
21 Yu B, Liu T, Du Y, Luo Z, Zheng W and Chen T: X-rayresponsive selenium nanoparticles for enhanced cancer chemoradiotherapy. Colloids Surf B Biointerfaces 139: 180-189, 2016.

22 Park SO, Yoo YB, Kim YH, Baek KJ, Yang JH, Choi PC, Lee JH, Lee KR and Park KS: Effects of combination therapy of docetaxel with selenium on the human breast cancer cell lines MDA-MB-231 and MCF-7. Ann Surg Treat Res 88: 55-62, 2015.

23 Qi Y, Fu X, Xiong Z, Zhang H, Hill SM, Rowan BG and Dong Y: Methylseleninic acid enhances paclitaxel efficacy for the treatment of triple-negative breast cancer. PLoS One 7: e31539, 2012.

24 Manikova D, Letavayova LM, Vlasakova D, Kosik P, Estevam EC, Nasim MJ, Gruhlke M, Slusarenko A, Burkholz T, Jacob C and Chovanec M: Intracellular diagnostics: hunting for the mode of action of redox-modulating selenium compounds in selected model systems. Molecules 19: 12258-12279, 2014.
Received August 24, 2016

Revised September 19, 2016

Accepted September 20, 2016 